\title{
Diversidade sexual e de gênero em instituições de acolhimento institucional: a invisibilidade de adolescentes LGBTIQA+
}

\author{
Sexual and gender diversity in institutional care services: the invisibility of LGBTIQA+ adolescents
}

\author{
Grazielly Ribas de Oliveira $^{\dagger *}$, Johnny Clayton Fonseca da Silva ${ }^{\dagger}$, Ana Cláudia de Azevedo Peixoto ${ }^{\S}$ \\ Como citar esse artigo. de Oliveira,

\section{Resumo}

G.R.; da Silva, J.C.F.; Peixoto, A.C.A.

Diversidade sexual e de gênero em

instituições de acolhimento institucional:

a invisibilidade de adolescentes

LGBTIQA+. Revista Mosaico, v.11,

n.2,p. 140-145, 2020.

O artigo trata-se de um mapeamento sobre o tema da diversidade sexual e de gênero no contexto de adolescentes acolhidos. Foram abordados acontecimentos históricos e atuais sobre sexualidade e sexo. Conjuntamente, levantou-se questões sobre adolescentes em situação de acolhimento institucional e seus direitos sexuais e sociais. O método utilizado foi o da Revisão Integrativa da Literatura, por meio das bases de dados SCIELO, BVS e LILACS. Trabalhou-se na busca de artigos publicados entre os anos de 2009 e 2019, em língua portuguesa e que estivesse dentro da temática. Não foi encontrado nenhum resultado dentro dos critérios metodológicos e a pesquisa caminhou para a exploração de indícios sobre os motivos da escassez de estudos com a temática. Concluiu-se que há uma distância entre o assunto tratado, a sociedade e o Estado, demonstrando uma significativa necessidade de investimento em pesquisa e ensino sobre diversidade sexual e de gênero no contexto de jovens acolhidos.

Nota da Editora. Os artigos publicados na Revista Mosaico são de responsabilidade de seus autores. As informações neles contidas, bem como as opiniões emitidas, não representam pontos de vista da Universidade de Vassouras ou de suas Revistas.

\begin{abstract}
The article is a mapping on the theme of sexual and gender diversity in the context of foster adolescents. Historical and current events on sexuality and sex were addressed. Together, questions were raised about adolescents in institutional care and their sexual and social rights. The method used was the Integrative Literature Review, using the SCIELO, BVS and LILACS databases. Work was carried out to search for articles published between 2009 and 2019, in Portuguese and within the theme. No results were found within the methodological criteria and the research moved towards the exploration of evidence on the reasons for the shortage of studies on the theme. It was concluded that there is a distance between the topic treated, society and the State, demonstrating a significant need for investment in research and teaching on sexual education in the context of young people fostered.

Keywords: Adolescents; Institutional Care; LGBTIQA+; Sexual and Gender Diversity.
\end{abstract}

\section{Introdução}

O presente artigo trata-se de uma Revisão Integrativa da literatura sobre diversidade sexual e de gênero no contexto de adolescentes acolhidos, que teve como objetivo levantar e analisar os artigos voltados para a temática sobre gênero e sexualidade entidades de acolhimento. Esse artigo é fruto de um trabalho de conclusão de curso e está vinculado ao Laboratório de Estudos Contra Crianças e Adolescentes (LEVICA), no qual se discute formas de ensino, pesquisa, prevenção e intervenção acerca dos diversos tipos de violência infanto-juvenil.

O LEVICA atende cerca de 60 crianças do sexo feminino e masculino, residentes nos municípios da Baixada Fluminense (Rio de Janeiro). O programa traça diálogos com instituições públicas e privadas, sendo estas de esferas educacionais, sociojurídicas, psicossociais, assistenciais e da saúde. Tais frentes, configuram o trabalho desenvolvido como multissetorial e multiprofissional (PEIXOTO, 2017; GALONI, 2018).

Para proporcionar uma melhor compreensão a respeito do que tem sido discutido no campo da sexualidade no contexto de jovens acolhidos, será apresentada um breve resgate histórico. Este resgate visa dimensionar o quanto os temas do sexo, sexualidade e juventude estiveram presentes em diversos saberes.

Afiliação dos autores:

†Mestranda em Psicologia / Programa de Pós-Graduação em Psicologia / Universidade Federal Rural do Rio de Janeiro (UFRRJ), Seropédica, RJ, Brasil.

${ }^{\ddagger}$ Doutorando em Psicologia / Programa de Pós-Graduação em Psicologia / Universidade Federal do Rio de Janeiro (UFRJ), Rio de Janeiro, RJ, Brasil.

${ }^{\S}$ Doutora em Psicologia / Docente do Programa de Pós-Graduação em Psicologia / Universidade Federal Rural do Rio de Janeiro (UFRRJ), Seropédica, RJ, Brasil.

* Email de correspondência: graziellycascon@gmail.com 


\section{Referências históricas e culturais sobre a sexualidade e o sexo}

Antes do século XVI, adultos e crianças partilhavam os mesmos ambientes domésticos, de trabalho ou lazer e não havia demarcações dos estágios do desenvolvimento cognitivo, subjetivo e comportamental. Neste cenário, as crianças tinham um déficit de poder sobre seus corpos em relação aos adultos. Após o período de dependência física da mãe, esses indivíduos se misturavam ao mundo adulto, sem proteção, mais expostos a doenças, violências e não exerciam função social antes de trabalharem e, por isso, era alta a taxa de mortalidade infantil (ANDRADE, 2010; OLIVEIRA, 2013).

Consequentemente, a construção do ser criança e do sujeito adolescente se dá a partir da herança histórica acerca da infância que por sua vez afetam as produções da nossa sociedade moderna (ANDRADE, 2010). Durante o Brasil Colônia, a proteção infanto-juvenil não era um direito. A Coroa Portuguesa visando atender seus interesses ministravam Catequeses em prol da moral e dos bons costumes dos habitantes(OLIVEIRA, 2013).

Quanto à sua sexualidade, as crianças foram consideradas assexuadas, puras, silenciadas e impedidas de ouvir e falar sobre questões sexuais. Este cenário acabava cultivando uma falta de conhecimento sobre o corpo infantil e se perpetuava através da repressão do comportamento (OLIVEIRA, 2013). A chegada dos Portugueses no Brasil instaurou novas formas de vivências, com práticas, valores, crenças e conhecimentos sendo repassados dos europeus para os indígenas (SFAIR; BITTAR; LOPES, 2015). Muitos hábitos foram subjugados e modificados pelos estrangeiros, um deles foi a nudez encontrada na cultura nativa, que foi interpretada como "falta de vergonha e pudor" (SFAIR et al, 2015).

A literatura sobre a história da sexualidade é marcada por alguns autores, dentre eles o filósofo francês Michel Foucault, que edifica o século XVII como "o início de uma época de repressão própria das sociedades chamadas burguesas, e da qual talvez ainda não estivéssemos completamente liberados" (FOUCAULT, 1988, p. 21). Para o autor, não é uma época marcada apenas pela censura sobre o sexo, mas sim para os mecanismos que deram base para a constante observação/vigia sobre o ato sexual. O sexo passa a ser visto como um mecanismo de poder, no qual, o discurso sobre o sexo passou a ser essencial (FOUCAULT, 1988).

O interesse social da época assegurava-se no discurso judaico-cristão e na economia dos prazeres individuais que por sua vez atuava no controle do que era exposto sobre o sexo. Existiam designações, regiões, relações sociais e pessoas que podiam falar sobre sexo. Esse formato instaurou regras de decência que oprimiam a curiosidade e a sensibilidade coletivas e contribuíam para o apagamento do prazer e de outras sexualidades (FOUCAULT, 1988).

Até o século XIX, as pessoas se relacionavam com indivíduos do mesmo sexo, sem o conceito da homossexualidade, do homoerotismo ou sem o termo homossexual (QUIJANO, 2005). Segundo Quijano (2005, p 126) o conceito formal da identidade homossexual é considerado um fenômeno moderno e construído numa "perspectiva de conhecimento e um modo de produzir conhecimento que demonstram o caráter do padrão mundial de poder: colonial/moderno, capitalista e eurocentrado".

A Igreja contribuiu para a massificação de uma ideologia repressiva com seu discurso de castidade, fidelidade e ingenuidade. A repressão à sexualidade tinha como aliada a instituição religiosa que visava a "mentalidade androcêntrica de subordinação, obediência e servidão da mulher em relação ao homem, incluindo a procriação de tantos filhos quanto "Deus" e a natureza determinarem". (BUGLIONE, 2002, p. 7)

No século XIX, algumas práticas sexuais, que eram julgadas pela sociedade como imorais, passaram a ser vistas como tema clínico de saúde para embasar a classificação das doenças. Eram usadas para ilustrar as transgressões e anomalias dos sujeitos e a necessidade de higienização e normalização do comportamento. Nesse contexto, a norma ganhou espaço de pleno controle sobre os corpos através do sexo e da sexualidade, assegurando o poder sobre os indivíduos (FOUCAULT, 1988; BUTLER, 2014)

No final do século XIX e início do século XX, Sigmund Freud contribuiu para a discussão da sexualidade, através das fases do desenvolvimento psicossexual - principalmente, a sexualidade infantil dando espaço para a construção de um discurso a respeito do sexo, como um elemento presente nas relações humanas que envolvem de forma holística a existência humana (FREUD, 1905).

O aparecimento da Psicologia, inicialmente, amparou-se no fundamentalismo católico e protestante, e as primeiras faculdades do saber psicológico eram católicas - revelando o interesse da religião em se apropriar dessa ciência (MAYA, 2019). Posteriormente a essa realidade, a ciência psicológica passou a ser engendrada no interior da medicina e operada como um equipamento do controle social e individual. Em virtude disso, o saber psicológico no final do XIX dispõe de uma forte presença de modelos patologizantes, individualizantes, assistenciais e curativos (GONÇALVES, 2010).

Em face a essa realidade histórica, nota-se que a busca do controle do comportamento sexual da população, desde o século XIX, vem sendo exercida por parte da medicina, que herdou da religião a liderança no 
assunto. Tal questão, por sua vez, expressa a submissão do corpo como parte de uma cientificidade que define o "normal" e o "patológico", criando barreiras e impedindo a livre expressão da sexualidade e dos direitos sexuais dos indivíduos e da sociedade como um todo (SFAIRet al, 2015).

Neste sentido que Uziel (2019, p. 48) questiona "por que se supõe ter sentido falar em normalidade quando o tema é sexualidade?". Com isto, aponta para a falta de sentido na dualidade entre o que é legítimo ou não, normal ou não, controlável e classificável. Fica à cargo da Psicologia a responsabilidade de tornar públicas as reflexões a respeito dessa "questão não ser uma questão" e tentar evidenciar "o que as motiva, quais são as forças que estão em jogo quando nos perguntam sobre a normalidade da sexualidade" (UZIEL, 2019, p. 48).

\section{Método}

O objetivo deste artigo foi mapear e analisar estudos sobre a diversidade sexual de adolescentes em situação de acolhimento institucional em âmbito nacional. A pesquisa teve carácter quantativoexploratório-descritivo e utilizou-se do método da Revisão Integrativa da Literatura.

A Revisão Integrativa da Literatura é considerada um método amplo e vantajoso, por possibilitar que a pesquisa siga em linhas experimentais e quaseexperimentais. Esse método objetiva proporcionar um panorama de um assunto específico, a partir de publicações anteriores. Em razão disso, é necessário estabelecer padrões de caráter metodológico que se baseiam em estudos bibliográficos, clareza na exposição dos resultados, de maneira que os aspectos sejam identificados pelos leitores (MENDES; SILVEIRA; GALVÃO, 2008).

A busca pelo material foi realizada através de plataformas digitais, chamadas de "Bases de dados online". Estas plataformas são bibliotecas virtuais nas quais podem ser encontrados resumos; artigos, dissertações, teses e livros e suas referências. Diante disso, optou-se por utilizar as seguintes bases de dados: SCIELO, BVS e LILACS.

Neste trabalho, foram estabelecidos os seguintes critérios de inclusão: artigos publicados somente em português e artigos publicados entre 2009 e 2019 - o recorte temporal foi pensado com efeito da discussão teórica estar presente na atualidade. E para os critérios de exclusão: teses, dissertações e/ou cartas e artigos que no resumo não tratem da temática.

Inicialmente, foram estabelecidos os seguintes descritores para a busca dos manuscritos: (1) [sexualidade], [adolescentes], [casa de acolhimento]; (2) [gênero], [adolescentes], [casa de acolhimento]; (3) [sexualidade]; [gênero]; [adolescentes],
(4) [casa de acolhimento]; (4) [diversidade sexual], [gênero],[adolescentes]; [casadeacolhimento]; $(5)$ [sexu alidade], [gênero], [diversidade sexual], [adolescentes], [casa de acolhimento]. O grupo de descritos acima se mostrou pouco sensível e não foram obtidos resultados.

Em função disso, foi necessária a combinação de mais descritores. Optou-se por combinar: (6) [sexualidade], [adolescentes], [abrigo]; (7) [gênero], [adolescentes], [abrigo]; (8) [sexualidade]; [gênero]; [adolescentes], [abrigo]; (9) [diversidade sexual], [gênero], [adolescentes], [abrigo]; e (10) [sexualidade], [gênero], [diversidade sexual], [adolescentes], [abrigo].

Foram encontrados um total de 151 textos nas três bases de dados, sendo 14 encontrados no LILACS, 136 no portal $B V S$ e 1 na SCIELO. Desses, 5 artigos eram repetidos, 117 estavam em língua estrangeira e 149 foram publicados antes de 2009 e tiveram que ser excluídos. Posteriormente, aplicou-se os critérios de inclusão, com o propósito de obter maior precisão na Revisão. Nesta etapa foram encontrados dois artigos. A última etapa debruçou-se na análise textual dos resultados encontrados.

\section{Resultados e Discussão}

Após a aplicação do método, identificou-se que o descritor "casa de acolhimento" não gerou resultados significativos. Tal fato se deve, amplamente, por ser um termo novo presente nas mudanças incorporadas ao ECA, através da, então, nova Lei de Adoção $\left(\mathrm{n}^{\circ}\right.$ 12.010/2009), que gerou reformas na política de acolhimento institucional e incentivou o desuso do termo, antes utilizado, "abrigo". Ao pesquisar com o descritor "abrigo" obtiveram-se mais resultados (BRASIL, 2009).

O descritor "diversidade sexual" também não apresentou resultados. Tal questão pode ser justificada pelo uso recente do conceito de diversidade sexual tratado como "orientação sexual". O conceito "orientação sexual" surge na década de 1980 e tem como objetivo substituir os termos "preferências e/ ou opções sexuais". O termo "diversidade sexual e de gênero" é ainda mais amplo e vem sendo utilizado, principalmente, pelo movimento Lésbicas Gays Bissexuais, Travesti, Transsexuais e Transgênero, Queer, Intersexo, Assexuais (LGBTQIA+) como forma de atender as múltiplas manifestações da sexualidade humana (REIS, 2018)

Os descritores "sexualidade, adolescentes e abrigo" obtiveram alguns resultados na plataforma BVS, porém os artigos não estavam dentro dos critérios de inclusão. A maioria dos artigos encontrados nessa combinação de descritores está relacionada à sexualidade no âmbito da saúde (gravidez na adolescência e DST/ AIDS). 
Ao longo da revisão permaneceram dois artigos, sendo eles com os seguintes títulos: "Violência vivenciada pelas adolescentes em situação de rua na ótica dos profissionais cuidadores do abrigo" e "Significados da maternidade e paternidade para adolescentes em processo de vulnerabilidade e desfiliação social".

Nesse ensejo, o artigo "Violência vivenciada pelas adolescentes em situação de rua na ótica dos profissionais cuidadores do abrigo" não entrou para análise. Com a leitura da publicação, constatou-se que o objetivo foi avaliar os tipos de violência que adolescentes de rua vivenciam a partir da ótica dos profissionais e não abordar as questões voltada para a sexualidade (PENNA; CARINHANHA; RODRIGUES, 2010).

$\mathrm{O}$ artigo "Significados da maternidade $e$ paternidade para adolescentes em processo de vulnerabilidade e desfiliação social" também não abordava a temática estudada. O artigo objetivou analisar problemáticas relacionadas à sexualidade vividas por adolescentes em situação de rua, com o foco no exercício da paternidade e maternidade (GONTIJO; MEDEIROS, 2010).

Cabe explicitar que o termo "gênero" é empregado nos artigos em relação às diferenças de gênero entre os sexos e não às questões de identidade de gênero. Com isto, nenhum artigo encontrado permaneceu para a análise crítica, sendo esta a última etapa da Revisão Integrativa. Diante deste resultado, foi perceptível uma escassez de publicações sobre a diversidade sexual de adolescentes acolhidos e uma necessidade de discutir possíveis indícios que refletissem a escassez do material com a respectiva temática.

Para Passos (2019), a discussão sobre minorias e diversidade sexual é uma discussão politizada que carece do que lhe é de direito: exercer genuinamente a diversidade. $\mathrm{O}$ autor afirma que o campo social, por vezes, se limita a acolher uma classe, gênero, etnia ou orientação sexual dominante. Porém, como afirma Figueiró (2006), a sexualidade humana é composta por vários outros elementos como sexo, prazer, afetividade, corpo, comunicação, e que estão integrados ao gênero, à identidade sexual e de gênero e à orientação sexual, resultando numa mais ampla definição.

Neste ensejo, Figueiró (2006) aponta para a dificuldade encontrada por parte de educadores, pais, autoridades políticas, instituições - e adultos de forma geral - em compreender, sistematicamente, que crianças e adolescentes nascem como sujeitos produtores de sexualidades. Desse modo, a invisibilidade, manipulação e exclusão da necessidade de uma educação sexual, seja em casa, na escola, em instituições de acolhimento, de medidas socioeducativas e ou qualquer outro ambiente, podem acarretar em prejuízos na formação da personalidade e na construção da identidade sexual dos adolescentes (FIGUEIRÓ; 2006; CASSAL et al, 2009; FERREIRA, 2018). pensando a partir do que se tem publicado em âmbito estatal. A partir de um mapeamento de documentos públicos sobre Educação Sexual no Estado de São Paulo, entre os anos de 1990 e 2000, Sfair et al. (2015) identificaram que $56 \%$ do material era provindo do Ministério da Saúde, enquanto apenas $12 \%$ provinha do Ministério da Educação. Ainda pelos aspectos analisados, as autoras identificaram que seu conteúdo sobre sexualidade era abordado ora de forma genérica, ora sobre riscos e aspectos morais sobre comportamento sexual. Isto mostra o quanto o discurso biomédico se faz presente nas discussões sobre educação sexual e não se promove uma discussão sobre sexualidade e diversidade sexual para além dos fatores de risco da prática sexual (FIGUEIRÓ, 2006).

Este silenciamento se torna mais agudo quando se trata de diversidade sexual em espaços institucionais, como casas de acolhimento, e no sistema sociojurídico. Segundo Ferreira (2018), as categorias profissionais que conduzem o serviço dentro do sistema estatal, por vezes, não se flexibilizam para o acolhimento imparcial das demandas, principalmente, de sujeitos LGTBTIQ. Isto alerta para a necessidade de reconhecer uma negligência histórica com os direitos humanos e sexuais dos sujeitos LGBTIQA+. São sujeitos oprimidos exatamente pelas expressões de sua sexualidade.

Em 2004, o Governo Federal lançou um programa intitulado "Brasil sem Homofobia", visando mensurar os crimes contra a população LGBTIQA+ e promover a equidade de direitos (FRANÇA, 2019). A partir disso, em 2011, o então Ministério da Educação desenvolveu o projeto "Escola sem Homofobia", no qual foi elaborado um material didático que seria distribuído às instituições educacionais em todo o país. Porém, antes mesmo do instrumento circular, grupos conservadores de parlamentares do Congresso Nacional e líderes religiosos fundamentalistas iniciaram uma campanha pressionando o então governo a impedir sua distribuição (MARÇAL, 2019).

A ferramenta pedagógica ficou apelidada, por estes grupos, como "kit gay", alegando que incentivava a promiscuidade e homossexualidade. Tal acontecido, expressa como pode ser custoso romper com os pensamentos e o poder dos conservadores reacionários que, historicamente, impedem a discussão sobre diversidade sexual e compõem a paralisação dos direitos da população LGBTIQA+. Mais que isto, essas reações fundamentalistas impedem que outros modos de se viver a diversidade sexual e de gênero, para além da heteronormatividade, seja pública e lhes resguarda a invisibilidade (MARÇAL, 2019; BICALHO, 2019).

Por fim, estes apontamentos também servem para evidenciar uma real distância que existe entre a diversidade sexual e de gênero, a educação sexual e a própria Psicologia, que enquanto ciência se propõe a atuar nas constituições de subjetividade dos sujeitos. 
Faz-se necessário que a Psicologia se comprometa em romper com um paradigma médico, que classifica e patologiza não somente expressões da sexualidade, mas sim, a própria diversidade sexual (GONÇALVES, 2010; NATARELLI et al., 2015; FERREIRA, 2018; BICALHO, 2019).

Vale citar um grande avanço, de fato, nesse compromisso da Psicologia, quando em 30 de janeiro de 2018 (Dia da Visibilidade Trans), o Conselho Federal de Psicologia publicou a resolução 01/2018 que "orienta os profissionais da Psicologia a atuar, no exercício da profissão, de modo que as travestilidades e transexualidades não sejam consideradas patologias" (CFP, 2018). O documento estabelece parâmetros de atuação de todo e qualquer psicólogo contra práticas que favoreçam uma cultura de discriminação, preconceito e patologização das pessoas transexuais e travestis e os convoca a promover o reconhecimento e a legitimidade da autodeterminação em relação às suas identidades de gênero (BICALHO, 2019).

Portanto, assim como sintetiza essa resolução, é preciso promover mais visibilidade às diversas expressões do campo da sexualidade. É preciso reconhecer a diversidade sexual para além dos contornos restritivos da heteronormatividade. São expressões que atravessam a sexualidade, sobretudo, dos adolescentes. O que está se convidando a refletir é sobre o próprio desenvolvimento destes sujeitos, sua personalidade, sua identidade, seus corpos, suas atuais e futuras relações interpessoais, amorosas, profissionais. Isto significa, contundentemente, atuar em favor da proteção destes sujeitos (NATARELLI et. al, 2015; BICALHO, 2019).

\section{Considerações Finais}

A partir da discussão sobre a escassez de material apontada pela revisão integrativa, notouse como o tema da diversidade sexual e de gênero com adolescentes, evidentemente, não é encontrado dentro da heteronormatividade, tão pouco dentro da homoafetividade. É possível perceber, portanto, uma distância entre a educação sexual e a juventude brasileira.

As temáticas da diversidade sexual e de gênero assumem ausências ainda mais expressivas, sobretudo, quando se faz um recorte pensando em adolescentesem situação acolhimento institucional. O ensino, o diálogo e a reflexão sobre sexualidade com adolescentes é considerado base para a prevenção de violências contra a população LGBTIQA+.

Em virtude disto, considera-se importante um constante estímulo às pesquisas acadêmicas na área, à formação de profissionais por uma perspectiva inclusiva e aliada contra toda forma de discriminação por gênero, orientação sexual, classe ou raça. Também neste sentindo, fica evidente a indispensabilidade de comunicação entre as diferentes instituições que compõem a vida do adolescente, como família, escola, saúde e assistência social, entre outras.

A inexistência de publicações na área limitou os resultados da pesquisa, demarcando a invisibilidade da existência de adolescentes LGBTIQA+ em situação de acolhimento institucional. Portanto, espera-se que este estudo, para além de traduzir um processo de angústia, possa inspirar outros profissionais pesquisadores, sobretudo os que trabalham com a prevenção e proteção social de crianças e adolescentes.

\section{Referências}

ANDRADE, L. B. P. Educação infantil: discurso, legislação e práticas institucionais [online]. São Paulo: UNESP; São Paulo: Cultura Acadêmica, 2010. 193 p. Disponível em: http://books.scielo.org/id/h8pyf/pdf/andrade9788579830853-06.pdf Acesso em: dez. 2019.

ANDRADE, P. SNA detalha estatísticas da adoção e do acolhimento no Brasil. Agência CNJ de Notícias, Brasília, Conselho Nacional de Justiça, 2020. Disponível em: https://www.cnj.jus.br/estatisticas-da-adocao-e-doacolhimento-no-brasil-sna/ Acesso em: abr. 2020.

BRASIL. Lei $\mathrm{n}^{\circ}$. 12.010, de 3 de agosto de 2009. Dispõe sobre adoção. Diário Oficial da União, 2009. Disponível em: http://www.planalto.gov.br/ ccivil_03/_ato2007-2010/2009/lei/112010.htm. Acesso em: jan. 2019.

BRASIL. Lei $n^{\circ} .8 .069$, de 13 de agosto de 1990. Dispõe sobre o Estatuto da Criança e do Adolescente e dá outras providências. Disponível em: http:// www.planalto.gov.br/ccivil_03/leis/18069.htm. Acesso em: out. 2019.

BRASIL, Ministério dos Direitos Humanos. Secretaria Nacional de Proteção dos Direitos da Criança e Adolescente. Letalidade infanto-juvenil: dados da violência e políticas públicas existentes. Documento eletrônico, 2018, 110 p. Disponível em: <http://www.mdh.gov.br/navegue-por-temas/crianca-eadolescente/institucional>. Acesso em: nov. 2019.

BICALHO, P. P. G. Psicologia e Diversidade Sexual: Muito a comemorar. Muito mais a fazer. In: FRANÇA, N. Psicologia e Diversidade Sexual: assim se passaram vinte anos. Rio de Janeiro: Conselho Regional de Psicologia do Rio de Janeiro, 2019. 2008p.

BUGLIONE, S. (org.). Reprodução e sexualidade: uma questão de justiça. Porto Alegre: Themis Safe, 2002. Disponível em: https://patriciamagno.com. br/wp-content/uploads/2014/08/PM_reproducao_e_sexualidade.pdf. Acesso em: nov. 2019

BUTLER, J. Regulações de gênero. Cadernos Pagu, FapUNIFESP, n. 42, p. 249-274, jun. 2014. Disponível em: http://www.scielo.br/pdf/cpa/n42/01048333-cpa-42-00249.pdf. Acesso em: nov, 2019.

CASSAL, L. C. B.; LAMEIRÃO, M .B. S.; BICALHO, P. P. G. Juventudes Rizomáticas: Problematizações da Sexualidade em Abrigos e Instituições de Cumprimento de Medidas Sócio-Educativas. Revista Contemporânea de Educação, Rio de Janeiro, Programa de Pós-Graduação em Educação, UFRJ, v. 4, n. 7, p. 132-147, 2009. Disponível em: https://revistas.ufrj.br/index.php/ rce/article/view/1578. Acesso em: nov. 2019.

CONSELHO FEDERAL DE PSICOLOGIA. Resolução nº 010/05. Aprova o Código de Ética Profissional do Psicólogo. Brasília, DF, 2005. Disponível em: <https://site.cfp.org.br/legislacao/codigo-de-etica/>. Acesso em: nov. 2019.

CONSELHO REGIONAL DE PSICOLOGIA. Psicologia e diversidade sexual. São Paulo, SP, 2015. Disponível em: < http://www.crpsp.org/fotos/ pdf-2015-11-05-16-12-10.pdf>. Acesso em: dez. 2019.

FRANÇA, N. Psicologia e Diversidade Sexual: assim se passaram vinte anos. Rio de Janeiro: Conselho Regional de Psicologia do Rio de Janeiro, 2019. 2008p

FERREIRA, G. G. Diversidade sexual e de gênero e o serviço social no 
sociojurídico. São Paulo: Cortez, 2018. 156 p.

FIGUEIRÓ, M. N. D. Educação Sexual: como Ensinar no Espaço da Escola Sexual. Linhas, n. 7 (1), 2006. Disponível em: http://www.periodicos.udesc. br/index.php/linhas/article/view/1323/1132. Acesso em: nov. 2019.

FOUCAULT, M. História da sexualidade 1: A vontade de saber. 3. ed. Rio de Janeiro: Graal, 1988

FREUD, S. Três Ensaios sobre a Teoria da Sexualidade. São Paulo: Schwarcz, 1905.

GALONI, L. L. Estudo de caso: aplicação do programa superar em uma adolescente vítima de abuso e exploração sexual. Trabalho de Conclusão de Curso. Instituto de Educação, Departamento de Psicologia, Universidade Federal Rural do Rio de Janeiro, Seropédica, RJ, 2018.

GONÇALVES, M. G. M.; Psicologia, subjetividade e políticas públicas. São Paulo: Cortez, 2010.

GONTIJO, D.T; MEDEIROS M. Significados da maternidade e paternidade para adolescentes em processo de vulnerabilidade e desfiliação social. Rev. Eletr. Enf. [online], v. 12 n. 4, p. 607-15 out/dez, 2010. Disponível em: http://dx.doi.org/10.5216/ree.v12i4.12340. Acesso em: abr. 2019.

MARÇAL, C. R. M.. Psicologia, diversidade sexual e políticas públicas ou sociais. In: FRANÇA, A. N. (org.). Psicologia e Diversidade Sexual: Assim se passaram vinte anos. Rio de Janeiro: Conselho Regional de Psicologia do Rio de Janeiro, 2019. 2008p.

MAYA, A.C.L. Por que é preciso que a religião tome a forma da psicanálise ou a psicanálise tome a forma da religião hoje? In: FRANÇA, A. N. (org.). Psicologia e Diversidade Sexual: assim se passaram vinte anos. Rio de Janeiro: Conselho Regional de Psicologia do Rio de Janeiro, 2019. 2008p.

MENDES, K. D. S; SILVEIRA, R. C. C. P; GALVAO, C. M. Revisão integrativa: método de pesquisa para a incorporação de evidências na saúde e na enfermagem. Texto contexto - enferm., Florianópolis, v. 17, n. 4, p. 758-764, 2008. Disponível em: https://doi.org/10.1590/S010407072008000400018. Acesso em: abr. 2019.

MICHELS, E. População LGBT morta no Brasil: Relatório 2018. Homofobia Mata, Grupo Gay da Bahia. Salvador, Bahia, 2018. Disponível em: https:// homofobiamata.files.wordpress.com/2020/02/relatorio.2018.2docx-2.pdf. Acesso em: dez. 2019.

NATARELLI, T. R. P; BRAGA, I. F · OLIVEIRA, W. A de; SILVA, M. A. I da. O impacto da homofobia na saúde do adolescente. Escola Anna Nery, Rio de Janeiro, v. 19, n. 4, p. 664-670, 2015. Disponível em: http://www.scielo. br/scielo.php?script $=$ sci arttext\&pid=S1414-81452015000400664 Acesso em: mai. 2019.

OLIVEIRA, T. C. Evolução histórica dos direitos da criança e do adolescente com ênfase no ordenamento jurídico brasileiro. Revista Interdisciplinar de Direito, v. 10, n. 2, out. 2013. Disponível em: < http://revistas.faa.edu.br/ index.php/FDV/issue/view/7>. Acesso em: dez. 2019.

PASSOS, E. Diversidade e política pública. In: FRANÇA, A. N. (org.) Psicologia e Diversidade Sexual: assim se passaram vinte anos. Rio de Janeiro: Conselho Regional de Psicologia do Rio de Janeiro, 2019. 2008p.

PEIXOTO, A. C. A. Um Estudo Qualitativo sobre os Pensamentos e as Distorções de Crianças e Adolescentes Vítimas de Violência. In: Anais do 11 Congresso Brasileiro de Terapias Cognitivas da FBTC. Foz do Iguaçu, Paraná, 2017. p. 16.

PENNA, L. H. G; CARINHANHA, J. I.; RODRIGUES, R. F. Violência vivenciada pelas adolescentes em situação de rua na ótica dos profissionais cuidadores do abrigo. Rev. Eletr. Enf. [online], v. 12, n. 2, p. 301-7, abr./ jun.2010. Disponível em: http://dx.doi.org/10.5216/ree.v12i2.5895. Acesso em: abr. 2019.

PEREIRA, M. E. et al. (org.). Gênero e diversidade na escola: formação de professoras/es em gênero, sexualidade, orientação sexual e relações étnicoraciais. Rio de Janeiro: CEPESC, 2009. 266 p. Disponível em: $<$ http://estatico. cnpq.br/portal/premios/2014/ig/pdf/genero_diversidade_escola_2009.pdf>. Acesso em: 01 jul. 2019.

QUIJANO, A. Colonialidade do poder, eurocentrismo e América Latina: a colonialidade do saber: eurocentrismo e ciências sociais. Perspectivas latinoamericanas. Buenos Aires: CLACSO, 2005. 142 p. Disponível em: http:// biblioteca.clacso.edu.ar/clacso/sur-sur/20100624103322/12 Quijano.pdf.
Acesso em: nov. 2019

REIS, T. (org.) Manual de Comunicação LGBTI+. Núcleo de Estudos AfroBrasileiros, Universidade Federal do Paraná, Curitiba, 2018. Disponível em: https://unaids.org.br/wp-content/uploads/2018/05/manual-comunicacaoLGBTI.pdf. Acesso em: nov. 2019.

SCHOEN-FERREIRA, T. H.; AZNAR-FARIAS, M.; SILVARES, E. F. M. Adolescência através dos séculos. Psic.: Teor. e Pesq. [online], v. 26, n. 2, p. 227-234, 2010. Disponível em: https://doi.org/10.1590/S010237722010000200004. Acesso em: nov. 2019.

SFAIR, S. C.; BITTAR, M.; LOPES, R. E. Educação sexual para adolescentes e jovens: mapeando proposições oficiais. Saúde e Sociedade, São Paulo, v. 24 , n. 2, p. 620-632, 2015. Disponível em: http://www.scielo.br/scielo. php?script=sci arttext\&pid=S0104-12902015000200620. Acesso em: dez. 2019.

SILVA, A. C. C. S., ADAN, L. F. F. Crescimento em meninos e meninas com puberdade precoce. Arq Bras Endocrinol Metab., n. 47, p. 422-31, 2003. Disponível em: http:/www.scielo.br/pdf/abem/v47n4/a14v47n4.pdf. Acesso em: out. 2019.

SILVA, J. C. F. da; GONÇALVES, S. M. M. Perfil da violência contra crianças e adolescentes segundo registros do Conselho Tutelar de um município da Baixada Fluminense. Revista Mosaico, 10 (2): 02-09, Jul/Dez 2019. Disponível em: http://editora.universidadedevassouras.edu.br/index. php/RM/article/view/1931. Acesso em: jan. 2020.

UZIEL, A. P. Diversidade sexual e binarismo. In: FRANÇA, A. N. (org.) Psicologia e Diversidade Sexual: assim se passaram vinte anos. Rio de Janeiro: Conselho Regional de Psicologia do Rio de Janeiro, 2019. 2008p. 